\title{
Lipids and cytokines: study in experimental model
}

\author{
P. D. Perris ${ }^{1}$, M. F. Godoy ${ }^{1,2}$, I. Fernandez ${ }^{1}$, C. Mambrin $^{1}$, M. C. Sanahuja ${ }^{1}$, E. M. Insani ${ }^{2}$, \\ N. H. Slobodianik ${ }^{1}$ and M. S. Feliu ${ }^{1}$ \\ ${ }^{1}$ Department of Nutrition and Food Science. Faculty of Pharmacy and Biochemistry, Buenos Aires, Argentina and \\ ${ }^{2}$ INTA-Castelar, Argentina
}

The importance of the diet in the maintaining of health statue is widely accepted and recognized. The influence of diets on immunocompetence is very important for no developing and developing countries, because the lack of appropriate food at weaning time is a critical factor for childhood malnutrition and predisposes to infection and death ${ }^{(1)}$. Dietary lipids have an important role, some fatty acids regulate immune and inflammatory processes, as they are precursors of molecules that mediate the inflammatory response. Cytokines are a huge group of molecules of great interest by their ability to regulate the immune response among other functions ${ }^{(1,2)}$. The aim of this work was to study the effect ofhigh-fat diets from different sources on some cytokines 1) pro-inflammatory: tumor necrosis factor-alpha (TNF- $\alpha$ ), interferon gamma (IFN- $\gamma$ )-derived cytokines Thelper-1, and 2) antiinflammatory: interleukin (IL)-4, a T helper2-derived cyto$\mathrm{kine}^{(3)}$. Weanling Wistar rats (21-23 days) divided into two groups were fed over 40 days with experimental diet containing $45 \mathrm{kcal} \%$ of fat provided by 1) high olive oil (AO group) and 2) butter (B group). The control group received a normocaloric diet (C). All diets containing $20 \%$ of protein and were complete in all others nutrients according to AIŃ93. At the end of the experiment, rats were sacrificed and blood was obtained. Serum levels of TNF- $\alpha$, IFN- $\gamma$ and IL- 4 were determined by ELISA method. Results were expressed as mean $\pm \mathrm{SD}$, with a significance level $* p<0.01$ by Student's $t$-test.

\begin{tabular}{|c|c|c|c|c|c|c|}
\hline \multirow[t]{2}{*}{ Group } & \multicolumn{2}{|c|}{ TNF- $\beta(\mathrm{pg} / \mathrm{ml})$} & \multicolumn{2}{|c|}{ IFN- $\delta(\mathrm{pg} / \mathrm{ml})$} & \multicolumn{2}{|c|}{$\mathrm{IL}-4(\mathrm{pg} / \mathrm{ml})$} \\
\hline & Mean & $\mathrm{SD}$ & Mean & $\mathrm{SD}$ & Mean & $\mathrm{SD}$ \\
\hline $\mathrm{AO}$ & $44.9 *$ & 12.0 & 64.0 & 28.8 & 0.6 & 0.3 \\
\hline B & $48.9 *$ & 4.2 & 140.7 & $73.7 *$ & 0.7 & 0.4 \\
\hline $\mathrm{C}$ & 31.3 & 5.4 & 32.1 & 6.0 & 0.7 & 0.4 \\
\hline
\end{tabular}

Results show higher levels of TNF- $\alpha$ in both experimental groups respect C; only B group show statistical higher levels of IFN- $\gamma$. Saturated fatty acids, provided by butter, would be acting as proinflamatory compounds. Although, other authors have demonstrated that oleic acid decreases the inflammatory processes by reducing the production of chemotactic molecules, in this work, we observed in group AO that TNF- $\alpha$ has a significantly increased and IFN- $\gamma$ shows a trend towards higher values not statistically significant. Such effect may be due to the high concentration of dietary lipids and the long period of rat's feeding. On the other hand, IL-4 values showed no significant differences. Both diets have a proinflammatory effect, either by the type of fatty acid present or by the high percentage of fat.

This study was supported by the University of Buenos Aires, Ref. 20020100200078.

1. Schaible UE \& Kaufmann SHE (2007) PLoS Med 4, e115.

2. Weaver KL, Ivester P, Seeds M, et al. (2009) J Biol Chem 284 (23):15400-15407.

3. Rocha VZ, Folco EJ, Sukhova G et al. (2008) Circ Res 103:467-476. 